\title{
Eliciting student feedback for course development: the application of a qualitative course evaluation tool among business research students
}

\author{
Carly Steyn, Clint Davies and Adeel Sambo
}

\begin{abstract}
Student evaluations of teaching and learning are playing an increasingly important role in the delivery of high-quality, student-centred education. Insights into student perceptions of their learning experience provide important information that can be used to inform course design and development. The majority of course evaluations take the form of quantitative surveys, but research suggests that a reliance on survey data alone can be problematic from a teaching and learning perspective. Qualitative course evaluations have been cited as a viable alternative to quantitative evaluations, but less research has been conducted into their efficacy when compared to quantitative evaluations. The study on which this article reports attempted to contribute to addressing this shortcoming by describing and assessing a novel approach to eliciting qualitative feedback from students in a research methodology course at a higher education institution in South Africa. Conventional content analysis was used to analyse the qualitative feedback received from students. The qualitative course evaluation approach was then appraised in terms of the degree to which it has the potential to overcome the shortcomings associated with quantitative course evaluations and the extent to which the information gathered could be used to improve the design and delivery of the academic programme.
\end{abstract}

\section{Introduction}

If implemented correctly, student evaluations of teaching and learning can play an important role in the delivery of quality higher education. While feedback from students about their learning experiences is predominantly used by universities to inform promotion and tenure decisions (Kember, Leung, and Kwan 2002) and aid professional development (Chulkov and van Alstine 2012), it can also provide valuable insights into the strengths and weaknesses associated with the delivery of a particular course or programme (Ahmadi, Helms, and Raiszadeh 2001; Shah and Nair 2009; Blair and Valdez Noel 2014; Mohammed and Pandhiani 2017). Furthermore, the data gathered from course and lecturer evaluations could provide university administrators with important insights into what motivates students and how to respond appropriately to students' changing needs (Grebennikov and Shah 2012; Smithson et al. 2015; Grebennikov and Shah 2017; Blair and Valdez Noel 2014). 
While the majority of student evaluations of teaching and learning take the form of quantitative course evaluation survey questionnaires (Erikson, Erikson, and Punzi 2016), research suggests that a reliance on survey data alone is problematic from a teaching and learning perspective (Alderman, Towers, and Bannah 2012; Trigwell, Caballero Rodriguez, and Han 2012). Qualitative feedback has been cited as a viable alternative to quantitative evaluations (Grebennikov and Shah 2013), but there is significantly less research into the efficacy of qualitative course evaluation methods when compared with quantitative methods.

The study on which this article reports contributes to addressing this shortcoming by reporting on a novel way of eliciting qualitative feedback from undergraduate students in a research methodology course. The technique was evaluated in terms of the extent to which it has the potential to overcome the shortcomings associated with survey-based evaluation techniques, and the extent to which the information gathered can be used to improve the learning experience of students.

\section{Literature review}

Course evaluations by students are a common and important feature of the higher education landscape. Also referred to as 'student evaluations of teaching' (SETs) or 'student ratings of instruction' (SRIs) (Linse 2017), these evaluations can take a number of forms, ranging from quantitative surveys to more complex qualitative methods. Because of their ease of administration and analysis, quantitative survey questionnaires are the most frequently used method of course evaluations internationally (Erikson, Erikson, and Punzi 2016). Quantitative evaluations of teaching and learning have, however, come under criticism from various sectors of the higher education community. The criticisms levelled against quantitative evaluations include their limited capability to contribute to course improvements (Huxham et al. 2008; Scott, Grebennikov, and Shah 2008; Shah and Nair 2009; Freeman and Dobbins 2013), questionable reliability and validity (Spooren, Brockx, and Mortelmans 2013) and low response rates (Dommeyer et al. 2002).

Because many quantitative course evaluations are designed with promotion and tenure decisions in mind they tend to be largely teacher-centric, comprising pre-defined response categories in a survey format. These techniques are significantly more judgemental rather than developmental in nature (Penny 2003), and do not capture the detail required to make meaningful course amendments that would benefit the student (Huxham et al. 2008; Smith 2008; Zhao and Gallant 2012; Freeman and Dobbins 2013; Blair and Valdez Noel 2014). The dimensions measured in quantitative course evaluation surveys also do not always reflect the student learning experience adequately (Chapple and Murphy 1996; Scott, Grebennikov, and Shah 2008). As a consequence, the findings from these surveys are seldom used for course development and improvement (Huxham et al. 2008). Kember, Leung, and Kwan (2002), for instance, considered data from course evaluation questionnaires at 25 universities, and found no evidence that the data gained from these questionnaires were used for course improvement.

Many quantitative feedback tools pre-suppose a'passive relationship'between students and lecturers, where students are considered to be'consumers of their learning as opposed to active participants and co-producers of the learning experience' (Freeman and Dobbins 2013, 145). As a 
consequence, students perceive quantitative evaluations as an exercise in compliance, and question the extent to which such evaluations are used to improve the student learning experience (Spencer and Schmelkin 2002; Chen and Hoshower 2003).

The validity and reliability of quantitative course evaluations remain a contentious issue (Spooren, Brockx, and Mortelmans 2013). While Benton and Cashin (2012) maintain that these evaluations are indeed a valid and reliable measure of student satisfaction, and that they should therefore be used for course development and improvement, others question their validity and reliability. Richardson (2005) maintains that a student's response to items on a course evaluation questionnaire may be influenced by a number of external factors affecting the validity of the instruments. Students' interest in the subject matter, their expected grades on the course in question, and their perceived workload have been shown to bias their evaluations of the learning experience. Research has also shown that students view quantitative course evaluations as an exercise in compliance (Gaillard, Mitchell, and Kavota 2011), and, as a consequence, tend to rush through the completion of these questionnaires without giving proper consideration to the questions at hand (Ahmadi, Helms, and Raiszadeh 2001).

Lecturers are also cited as questioning the accuracy of these assessments; and are therefore reluctant to let their results inform course development (Aleamoni 1999; Darwin 2017). Based on interviews with staff from three tertiary institutions in New Zealand, Stein et al. (2013) reported that many lecturers view course evaluations as a popularity contest and therefore do not take the results seriously. Quantitative student evaluations are also plagued by lower response rates when compared with qualitative methods (Dommeyer et al. 2002), making non-response error a common characteristic (Guderand Malliaris 2013).

Most quantitative course evaluations take the form of questionnaires employing Likert-type scales where students are asked to indicate their levels of satisfaction or dissatisfaction on a range of factors, including quality of teaching, course content and material and aspects related to the general student experience (Smithson et al. 2015). In such cases, the statistical mean is generally used to interpret the data. But, because the data gathered in these types of surveys are categorical, the statistical mean becomes an imprecise indicator and does not represent the diversity of the student experience (Smithson et al. 2015).

In light of the criticisms levelled against quantitative course evaluation, scholars and practitioners alike have called for the use of more holistic and meaningful methods to measure student perceptions of their teaching and learning experiences (Alderman, Towers, and Bannah 2012; Cathcart, Greer, and Neale 2014). Qualitative feedback has been cited as a viable alternative to quantitative evaluations (Scott, Grebennikov, and Shah 2008; Shah and Nair 2009; Grebennikov and Shah 2013) as it is purported to elicit a richer and more diverse picture of the student learning experience (Kabanoff, Richardson, and Brown 2003; Kindred and Mohammed 2005; Davison and Price 2009).

While significantly less research has been conducted into the advantages of qualitative course evaluation techniques when compared with quantitative methods (Chambers 2010; Grebennikov 
and Shah 2013), recent research has endeavoured to address this shortcoming (Hoon et al. 2015; Erikson, Erikson, and Punzi 2016; Stupans, McGuren, and Babey 2016; Veeck et al. 2016; Brandl, Mandel, and Winegarden 2017; Varga-Atkins, McIsaac, and Willis 2017). Scholars who have compared qualitative evaluation tools with quantitative techniques have found qualitative techniques to offer a number of advantages (Huxham etal.2008).

The most frequently cited advantage of qualitative student feedback techniques is that they provide insight into aspects of teaching and learning that are not normally covered by existing quantitative methods (Kabanoff, Richardson, and Brown 2003; Scott, Grebennikov, and Shah 2008). Because qualitative course evaluations do not rely on pre-defined response categories that reflect a specific teaching and learning paradigm, they provide students with the opportunity to generate their own issues and ideas regarding the teaching and learning processes that characterise higher education. For example, Kabanoff, Richardson, and Brown (2003) show how the analysis of qualitative comments from business graduates uncovers numerous themes which point to aspects of the student experience that are not normally captured in quantitative evaluations. Through qualitative evaluation techniques, a more holistic, representative view of the student experience is captured, resulting in meaningful information that can be used to improve the teaching and learning processes underpinning a course (Stupans, McGuren, and Babey 2016).

Research also suggests that students regard the provision of qualitative feedback as more meaningful and valuable when compared with quantitative feedback (Davison and Price 2009; Hoon et al. 2015). Qualitative feedback techniques empower students to make a meaningful contribution to the teaching and learning process and treat students like active contributors to the learning experience (Cook-Sather 2006; Hoon et al. 2015).

Students particularly favour qualitative course evaluations that elicit group feedback (Dobbie et al. 2004; Nestel et al. 2012), and numerous studies have found that collaborating with peers in the evaluation process leads to greater engagement in the process (Wickramasinghe and Timpson 2006; Finelli, Wright, and Pinder-Grover 2010; Chad 2012; Veeck et al. 2016). In a study combining focus group and nominal group techniques, Varga-Atkins, McIsaac, and Willis (2017) found that students enjoyed the group setting as the views of others helped draw out their own individual experiences and responses.

Qualitative feedback methods are, however, not devoid of disadvantages. Qualitative feedback takes significantly longer to analyse (Brockx, Van Roy, and Mortelmans 2012) and requires significantly more resources (Richardson 2005) than quantitative feedback to do so. As a consequence, lecturers may be reluctant to use qualitative course evaluation methods and instead make use of course evaluation surveys, which are easier to administer.

Based on the literature, it would appear that qualitative course evaluations do offer advantages when compared with quantitative evaluations, but that these advantages may be overshadowed by the implementation and analysis of qualitative evaluations being time consuming and resource intensive. Since less research has been conducted into the implementation and analysis of qualitative course evaluations when compared with quantitative evaluations (Chambers 2010; 
Wongsurawat 2011; Grebennikov and Shah 2013), more research is needed to explore the potential role that qualitative course evaluations can play in course design and development. In so doing, additional insights into the relative advantages and disadvantages of using qualitative course evaluations can be explored. Such research would inform more robust engagement and debate regarding the choice of when to use qualitative course evaluations and when to opt for quantitative evaluations. The present research aimed to contribute to this debate by describing and evaluating a qualitative course evaluation tool used to elicit student perceptions of an undergraduate business research methods course.

\section{Qualitative course evaluation used in the present research}

At the institution where the present research was undertaken, course evaluations generally take the form of anonymous quantitative survey questionnaires that are administered at the end of the semester. Through these questionnaires, students are asked to indicate the extent to which they agree or disagree with each of 27 statements using a 5-point Likert-type scale where $1=$ strongly agree and 5 = strongly disagree. The items included in the questionnaire cover different areas of the teaching and learning experience, such as lecturer quality and preparedness, student involvement in learning, and student perceptions of assessment activities. A comment section is also provided, in which students are invited to make any additional comments. This section generally elicits a low response rate from students. Student responses to the questionnaire are automatically captured and a summary of responses is returned to the lecturer or head of department.

The qualitative course evaluation method on which the present research was based was designed to elicit written qualitative feedback from undergraduate commerce students on their perceptions of the learning experience in a business research methods course. A total of 220 students were registered for the course, and represented a number of degree programmes such as finance, law, industrial psychology and general management. The course runs for a total of 13 weeks across one semester. In addition to two one-hour lectures per week, students are required to participate in a weekly one-hour tutorial led by a postgraduate tutor or teaching assistant. Each tutorial class comprises $15-30$ students and aims to provide students with the opportunity to apply the theory covered during lectures in smaller group settings under the guidance of a tutor.

The qualitative course evaluation on which this article is based was designed to take place during the final tutorial of the semester. In the two weeks prior to the tutorial, students had completed a series of lectures on experimental research design and were required to apply the theory covered in class by designing and conducting an experiment to test whether groups are more effective in generating ideas than when the same number of individuals work independently. The research problem on which the experiment was based was taken from Blumberg, Cooper, and Schindler (2011). As part of the exercise, students were also provided with a topic to use as the basis for idea generation. The topic for idea generation was: 'What can the lecture and tutorial team do differently to improve the Business Research course for future student cohorts?'The instructions given to students at the start of the tutorial appear as Table 1. 
As per the instructions, each tutorial class was instructed to design an experiment to address the research problem. A total of ten tutorial classes completed the exercise, and tutorial class sizes ranged from ten to 25 students.

Table 1. Tutorial instructions for students and tutors.

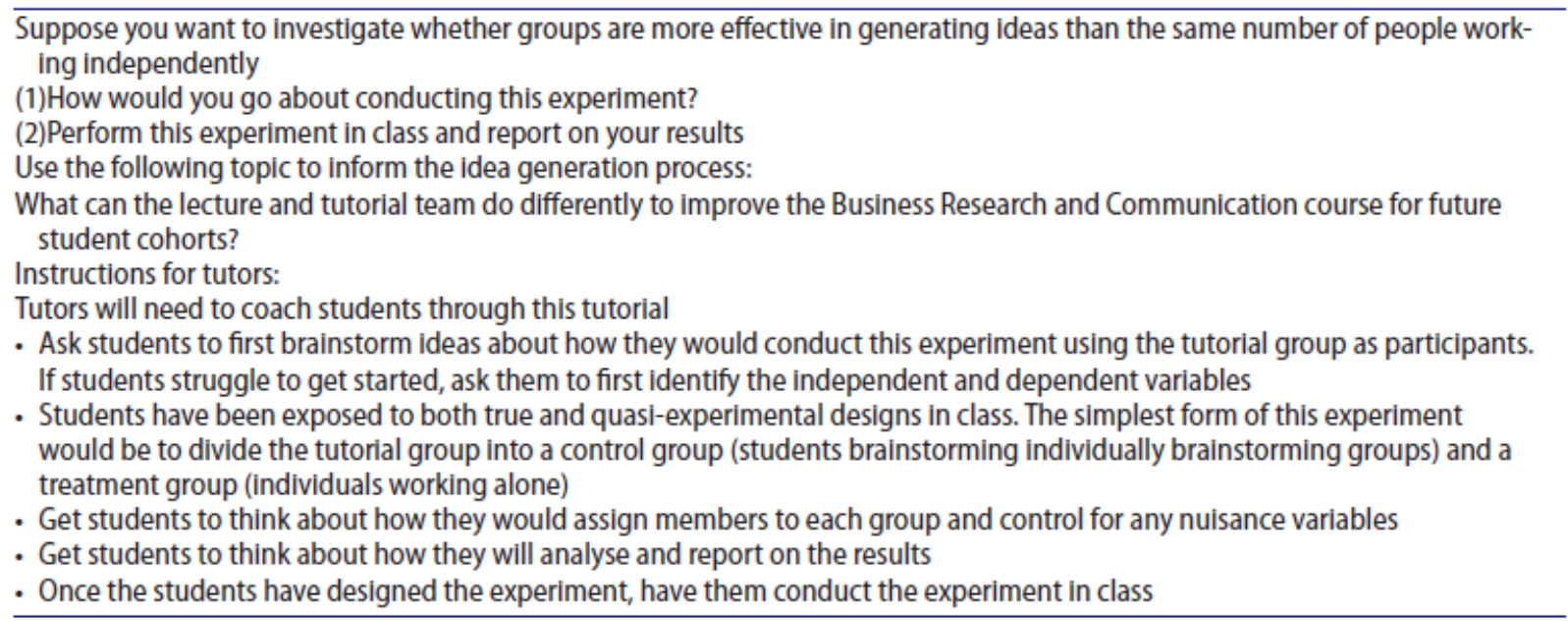

All tutorial classes chose an experimental design comprising a control (students brainstorming individually) and treatment group (brainstorming groups). Students used either a process of matching or randomisation to assign themselves to treatment or control groups. After both control and experimental groups had been allowed a set amount of time, students compared the number of ideas generated by the control group with the number of ideas generated by the treatment group.

\section{Research design and methodology}

During the tutorial exercise described above, the students in both the treatment and control groups were given feedback forms onto which to record their suggestions as to how the course could be improved for future cohorts. Each tutorial was facilitated by a postgraduate tutor who informed students that their suggestions would be used to inform course development and that their anonymity would be guaranteed. Once the tutorial exercise had been completed, tutors collected the worksheets from groups and individual students, providing the research team which a rich and varied collection of recommendations from students about how the course could be improved.

The group and individual responses obtained through the exercise were used as the qualitative data on which this article is based. In addition to the qualitative feedback received from students, it was important to obtain feedback regarding the administration and implementation of the feedback exercise. To this end, tutors were requested to provide reflective feedback of their experiences while facilitating the exercise.

Tutors were requested to provide feedback in response to the following questions: 
Reflect on any challenges you faced in applying the course evaluation method.

Written feedback in response to the questions above was obtained from two of the three tutors who facilitated the exercise.

\section{Analysis of the data}

The tutors transcribed the recommendations received from students verbatim. They then proceeded to analyse the data using conventional content analysis. This was deemed the most appropriate method for the current study as it is based on 'participants' unique perspectives and grounded in the actual data' (Hsieh and Shannon 2005, 1279). After removing 64 statements that were not phrased as recommendations or that did not relate to the topic under investigation, a total of 481 recommendations formed part of the data to be analysed. On average, groups generated slightly more recommendations ( 3.8 per group) than their individual counterparts ( 3.5 per individual).

An initial coding scheme was developed by allowing codes to emerge inductively from the data. Codes were then sorted into themes and discussed within the team of three tutors until consensus was reached. The lecturer conducted an independent analysis of the data and compared codes and themes with the tutors, after which a final coding scheme was agreed upon. A total of 27 codes were agreed upon and condensed into eight themes.

Feedback from thetutors on theimplementation of the course evaluation method was analysed by the lecturer using conventional content analysis.

\section{Findings}

The analysis of the data identified eight broad areas of student experience where improvements could be made. These included curriculum/course content, staff quality, assessment, learning support, teaching methods, teaching and learning resources, course administration and the learning environment. Each of these broad categories of student experience can be broken down into smaller sub-categories. Table 2 provides a tabular description of the codes assigned when analysing the data. The numbers in brackets indicate the number of student recommendations that correspond to a specific code.

The largest proportion of student suggestions/recommendations related to assessments (34.7\%). These could be classified as recommendations relating to assessment standards, structure, schedule, criteria and feedback. Recommendations regarding staff were the second most frequently cited (17.3\%), and included references to tutor and lecturer availability, teaching skills, quality and frequency of communication with students and the number of lecturers on the module. Of the recommendations, $12 \%$ were related to the learning environment. Here students made reference to quality of lecture hall equipment, the size and comfort of lecture and tutorial venues and the quality of the learning environment created through group project work. Recommendations relating to learning support also comprised $12 \%$ of the total recommendations. Here students made 
suggestions related to adequate preparation for assessments and the provision of additional learning support, such as workshops and guest lecturers.

Just over $10 \%$ of recommendations related to the provision of teaching and learning resources. These included suggestions related to the provision of additional resources and the quality, timeliness and affordability of resources provided. Of the recommendations, $6 \%$ related to teaching methods, and included suggestions to make the lectures more interactive and application-based. Another $4 \%$ of the recommendations were associated with the curriculum or course content, and included references to the relevance of the curriculum and the workload. Administration-related suggestions around class scheduling and suggestions comprised $3 \%$ of the total recommendations made.

The reflective feedback received from the tutors who facilitated the exercise revealed six broad themes, namely process planning, data analysis, student perceptions of the process, facilitator conduct, student learning and student participation. The theme that emerged most frequently in the tutor reflections pertained to student reactions to the qualitative course evaluation method. Tutors reported that students were generally engaged in and energised by the process. Tutors also reflected on the rigorous planning and co-ordination required to run the exercise successfully, and to ensure that quality data was collected. Through their reflections, tutors shared their perceptions of the student learning experience by referring to the ways in which students planned and conducted the experiment, and the challenges they faced in carrying out the experiment.

\section{Discussion}

Based on the findings, the qualitative course evaluation provided a student-centred account of the teaching and learning experience associated with the course. And because student feedback was received in the form of recommendations as to how the course could be improved, the data can be used to inform meaningful course amendments. But not all feedback received from students proved constructive. Because unstructured recommendations were elicited, not all recommendations can be regarded as feasible from an academic and implementation perspective. Furthermore, the data obtained through the evaluation required considerable time and resources to analyse. 
Table 2. Main and sub-themes emerging from the analysis.

Main and sub-themes

Main theme 1: Course content and curriculum

- Relevance

Frequency

$\%$ of total

- Workload

Main theme 2: Assessment

- Assessment schedule

- Assessment standards

- Assessment structure

- Assessment criteria

- Quality of assessment feedback

- Provision of timeous feedback

Main theme 3: Staff

- Availability

- Lecturer teaching skills

- Tutor teaching skills

- Staff responsiveness to student needs

• Number of lecturers on programme $\quad 11$

- Internal communication between lecturers and tutors $\quad 7$

Main theme 4: Learning support $\quad 58$

- Preparation for assessments $\quad 37$

$12.1 \%$

- Additional support in the form of workshops and guest lecturers 21

Main theme 5: Teaching methods

- More opportunities for application

- Greater interaction

Main theme 6: Teaching and learning resources

- Quality of resources

- Timeous release of resources

- Additional resources

- Affordability of resources

Main Theme 7: Administration

- Ease of Submissions 
Table 2. (Continued).

\begin{tabular}{lcc}
\hline Main and sub-themes & Frequency & $\%$ of total \\
\hline Main theme 8: Learning Environment & 58 & $12.0 \%$ \\
- Infrastructure and equipment & 9 & \\
- Venue comfort & 22 & \\
- Group work environment & 27 & $100 \%$ \\
Total & 481 & \\
\hline
\end{tabular}

The primary advantage of the course evaluation method used in the present research is that it provides a holistic account of the student experience on the course. The course evaluation method provides insights into the dimensions of teaching and learning that are relevant to students when reflecting on their learning experience. As mentioned, the institution under investigation typically makes use of a structured survey questionnaire to elicit feedback from students. The dimensions covered in the questionnaire reflect a somewhat narrow, teacher-centric view of the student learning experience and are limited to lecturer quality, teaching and learning resources, perceptions of assessments and the tutorial programme. Through the use of the current qualitative evaluation method, additional dimensions relating to course content, learning support, the learning environment and course administration were revealed, resulting in an extensive examination of the student experience. Furthermore, the dimensions which emerged through the qualitative course evaluation described above corresponded more closely to the components that characterise good teaching as identified by Crumbley, Henry, and Kratchman (2001), Spencer and Schmelkin (2002) and Alhija (2017) than the dimensions covered in the quantitative course evaluation questionnaire used at the institution.

Although the themes that emerged from our study cover more components of the student learning experience than the feedback questionnaires used by the institution, it is possible that the entirety of the student experience was still not captured. For instance, issues relating to student progression and retention, cultural diversity and equity were not touched on by the students. By eliciting unstructured qualitative feedback from students, one runs the risk of not receiving sufficient feedback on issues that may be relevant to the academic project. For instance, while recommendations relating to course content and relevance are undoubtedly important to lecturers and academic administrators, they only constitute $4.4 \%$ of the recommendations made. As indicated by Chapple and Murphy (1996), factors related to the nature of the material being taught may not immediately be evident to students when evaluating their learning experiences, and may be overshadowed by a focus on the aspects related to the presentation of the course.

Due to their restricted knowledge of the higher education system, students may also make recommendations that are impractical from a 'financial or logistical' perspective (Dobbie et al. 2004, 405). Students might also make suggestions that'may not correlate with their educational needs'(Dobbie et al. 2004, 406). For instance, many students in our sample reported dissatisfaction 
that they were assigned to groups with students with whom they had not previously worked. Regardless of their dissatisfaction with the composition of their groups, students do stand to benefit from exposure to diverse groups.

Recommendations regarding assessment comprise the largest proportion of suggestions made by students during the course evaluation. In an analysis of 3,500 open-ended responses from undergraduate students at a large metropolitan university in Australia the aspect that attracted the most recommendations for improvement were also related to assessment (Scott, Grebennikov, and Shah 2008). Similarly, in a study of the relative importance of various teaching dimensions as evaluated by Israeli students, assessment was regarded as the most important dimension (Alhija 2017). Teaching methods and long-term student development were regarded as less significant when compared with assessment. In particular, fair assessment and useful feedback were regarded as the two most important characteristics of good assessment. According to Alhija (2017), this is to be expected amongst undergraduate students, as grades are important considerations for enrolment in further studies and for securing worthwhile employment. The results of our research also point to the importance that students placed on assessment. It could be argued, however, that an 'assessment mentality' among students may have overshadowed the importance of some of the other dimensions of the student learning experience.

According to Hoon et al. (2015), many qualitative course evaluation methods elicit purely descriptive feedback from students. The course evaluation method used in the present research goes beyond merely eliciting descriptive feedback by eliciting recommendations from students on how the course could be improved. As a result of this constructive feedback from students, the data can be used to inform meaningful changes in course content and method of delivery.

The method is, however, limited in terms of the extent to which the data can be used for promotion and tenure decisions. Since the feedback received from students takes the form of recommendations about how the course could be improved, it only reflects the shortcomings associated with a particular course as perceived by the students. Data used for promotion and tenure decisions should ideally reflect a balance between the strengths and the weaknesses associated with a particular course and its delivery. By exclusively eliciting recommendations from students about how the course could be improved, positive feedback is inhibited.

The design of a feedback methodology should therefore be informed by the use for which it is intended. If feedback is to be used for course or lecturer improvement or development, it should be informed by an 'improvement approach' (Golding and Adam 2016,11) and function as a window into the student learning experience. Such methods should adopt a student-centred approach to course evaluation, as opposed to the personal judgement approach, which often characterises evaluations that are designed for the purposes of promotion and appraisal.

A further advantage of the exercise is that, while it provides university educators and administrators with detailed qualitative feedback pertaining to a course, it simultaneously provides students with a practical exercise related to the course content. While we did not collect data from students measuring the extent to which they benefitted from the exercise, feedback gathered from the 
tutor facilitators showed that students were eager to participate in a practical exercise through which to apply their theoretical knowledge of experimentation. Reflections from one of the tutors indicated that students 'expressed that the exercise enabled them to understand experimentation better through the implementation thereof'. In another instance, the tutor noted, 'students were overwhelmed with zeal as they were eager to participate in a research study'.

Research has shown how students appreciate the opportunity to provide qualitative feedback pertaining to their learning experiences (Cook-Sather 2006). Feedback from the tutors who facilitated the exercise suggests that students found the exercise engaging and meaningful. For instance, one tutor noted, '[the] students seemed to have enjoyed the class. It seemed that they were in fact gladdened to have the opportunity to share their thoughts. Another tutor wrote, 'students complemented the method as it enabled them to provide truthful data without divulging any personal information'. One tutor did ask a group of students for feedback after the exercise and received the following comments: 'It is better than providing students with a questionnaire to complete during the lectures', 'I feel that this method will result in some effective changes' and 'A fun way to collect data'.

As Darwin (2017) rightfully notes, the legitimacy of student evaluations needs to be enhanced in the current higher education context. To this end, evaluations need to embody a bias for negotiated, development-focused action, which explicitly engages participants in a form of collaborative dialogue' (Darwin 2017, 20). The evaluation method reported on in this article engaged students as active and valued co-creators of the learning experience by eliciting constructive suggestions about how the learning experience could be improved. By asking students to think of ways to improve the course, as opposed to just asking them to evaluate it, thoughtful responses were elicited. It is argued that these responses are of more value than the critical evaluations that are gathered through survey evaluations.

Depending on whether they were assigned to the treatment or the control group, students provided recommendations as individuals or in groups. While it is beyond the scope of this paper to report on the results of the experiment conducted by the students to determine whether groups are more effective in generating ideas than when the same number of individuals working independently, our findings do show that, on average, groups did generate slightly more recommendations when compared with their individual counterparts. This suggests that students who provided feedback in groups may have enjoyed an advantage over their peers who worked individually. Although we did not collect data from students regarding their experience with the course evaluation method, previous research suggests that students benefit from a group setting (Dobbie et al. 2004; Nestel et al. 2012).

What we do not know, however, is whether group processes played a negative role in the evaluation process. By obtaining feedback in a group setting one always runs the risk that only the most vocal and dominant members of the group will have their voices and concerns heard (Chapple and Murphy 1996). Because the exercise was aimed at determining whether groups or individuals are better at coming up with ideas, it could be argued that students were in a competitive frame of mind and did therefore not censor their ideas. One could argue that all ideas, even minority ideas, were recorded 
and captured. It is also, however, likely that the responses collected from groups represent individual contributions, since groups were not asked to reach consensus on their recommendations.

One of the primary criticisms against qualitative course evaluation tools is that they require considerable time and resources to administer and analyse. The course evaluation tool used in the current research required considerable co-ordination and planning between tutors to ensure that the process ran smoothly and that quality data was collected. As both of the tutor facilitators noted in their reflections:'Proper planning and close monitoring of the experiment ensured that quality data was obtained', and'Proper planning and controlled systems ensured that the data was similarly collected for all groups' The analysis of the data also required the allocation of significant resources. The three tutor facilitators were responsible for transcribing and coding the data. Codes were then discussed within the team of tutors until consensus was reached, and then classified into themes. The lecturer conducted an independent analysis of the data and compared codes and themes with the tutors after which a final coding scheme was agreed upon.

Despite the significant resources required to collect and analyse the data, the exercise proved extremely valuable, and the data generated has been used to inform the development and delivery of the course for future cohorts. But because of the considerable resources that need to be allocated to the administration and analysis of a course evaluation of this nature, it would prove onerous to run the exercise annually.

\section{Recommendations}

Because the course evaluation method presented in this research elicits unstructured feedback from students, one runs the risk that important aspects related to the academic project are not evaluated. Students possess only partial knowledge of the higher education system, and may, as a result, not provide feedback on all aspects that faculty might regard as relevant from a course development and improvement perspective. One way to address this shortcoming is to make use of a structured question proforma, which includes specific open-ended questions related to particular areas of interest. As Newton, Wallace, and McKimm (2012) and Hoon et al. (2015) show, the use of a structured question proforma is associated with richer feedback from students when compared with a free-text proforma. The evaluation method used in the current research could therefore be amended by requiring students to provide suggestions relating to specific pre-determined dimensions of the teaching and learning experience.

Another shortcoming associated with the qualitative course evaluation methodology is the considerable time and resources it takes to implement and analyse. Applying a qualitative course evaluation methodology of this nature on an annual basis is likely to prove extremely onerous and time-consuming in most higher education contexts. This limitation can be partly overcome by alternating the use of qualitative and quantitative evaluations in such a way that they complement each other, as proposed by Harper and Khu (2007) and Darwin (2017). For example, the themes that have emerged through this qualitative course evaluation exercise could inform the design of a structured survey questionnaire, which could be administered every second year as an alternative 
to the qualitative evaluation. In so doing the administrative burden associated with implementing qualitative evaluations on an annual basis could be overcome.

\section{Limitations of the research}

Given that only 161 of the 220 students enrolled in the course participated in the evaluation exercise, our study is at risk of non-response error. This is a common problem associated with course evaluations that are conducted at the end of a semester. According to Wolbring and Treischl (2016), the quality of the course, course timing and workload are all factors that influence absenteeism towards the end of the semester when course evaluations typically take place. The authors found, however, that average ratings do not change significantly after adjusting for selection bias.

Another limitation of our research is that we did not collect information regarding the extent to which students were satisfied with the evaluation process. Brandl, Mandel, and Winegarden (2017) conducted course evaluations through the use of a focus group setting, which comprised students, the course director, academic deans and other faculty members involved in the design and delivery of the course. Their research showed that students valued the process and that their satisfaction with the process improved significantly when compared with other forms of student evaluations.

A final limitation relates to the actual qualitative evaluation tool used in the research. Because the evaluation requires students to design and participate in an experiment, it is only applicable for use in research methodology courses where experimentation is taught as a component of the course. The methodology can obviously be adjusted for other courses by requiring students to make recommendations about how the course could be improved for future cohorts. In doing so, however, one would lose the opportunity to combine a course evaluation with a teaching and learning activity.

\section{Conclusion}

Student evaluations of teaching and learning are an important feature in higher education, providing information on the standard of teaching and the quality of courses offered. Research suggests that the preferred method for evaluating the teaching and learning experience of students is through the quantitative course evaluation survey, as it is perceived as more objective and reliable and less labour and time intensive when compared with qualitative approaches. As a consequence, significantly less research has been conducted into the efficacy of qualitative course evaluations. The present research attempted to address this gap by describing and assessing the implementation of a qualitative course evaluation tool for use among business research students. Our findings support those of other scholars, who suggest that qualitative course evaluations provide a more holistic, student-centred perspective of the student experience when compared with quantitative evaluations. Qualitative approaches provide a deeper, more context-specific perspective of the student experience, providing insights that are generally regarded as more relevant to the improvement of teaching and learning outcomes.

We do, however, concur with other scholars that qualitative course evaluations present challenges from a both a time and resource perspective. We therefore recommend that higher education 
institutions that wish to promote student-centred, quality higher education use qualitative course evaluation approaches in concert with quantitative approaches. As shown through this research, qualitative course evaluations have the potential to offer important insights into the dimensions of teaching and learning that students regard as relevant, and can therefore serve as important resources in course design and development. Moreover, the themes that emerge from qualitative course evaluation can be used to inform the development of more holistic, context-specific and student-centred quantitative evaluations that can be used to inform course improvement and innovation.

\section{Disclosure statement}

No potential conflict of interest was reported by the authors.

\section{Notes on contributors}

Carly Steyn is a senior lecturer in Research Methodology and Organisational Behaviour at the School of Business and Finance, University of the Western Cape. Her research interests include leadership development, positive organisational psychology and employee well-being.

Clint Davies is a business management lecturer and research assistant at the Department of Business Management, University of Pretoria. $\mathrm{He}$ is currently completing his $\mathrm{PhD}$ in Entrepreneurship. While completing the research on which this article is based, Davies was a lecturer and tutor co-ordinator at the School of Business and Finance, University of the Western Cape.

Adeel Sambo is a lecturer in Research Methods at the School of Business and Finance, University of the Western Cape. He is currently undertaking a $\mathrm{PhD}$ focusing on entrepreneurship in the informal sector.

\section{ORCID}

Carly Steyn http://orcid.org/0000-0002-9609-8457

Clint Davies $\quad$ http://orcid.org/000o-0002-2477-6466 


\section{References}

Ahmadi, M., M. M. Helms, and F. Raiszadeh. 2001. "Business Students' Perceptions of Faculty Evaluations." International Journal of Educational Management 15 (1): 12-22.

Alderman, L., S. Towers, and S. Bannah. 2012."Student Feedback Systems in Higher Education: A Focused Literature Review and Environmental Scan." Quality in Higher Education 18 (3): 261280. doi:10.1080/13538322.2012.730714.

Aleamoni, L. M. 1999. "Student Rating Myths versus Research Facts from 1924 to 1998." Journal of Personnel Evaluation in Education 13: 153-166.

Alhija, F. N. A. 2017. "Teaching in Higher Education: Good Teaching through Students'Lens."Studies in Educational Evaluation 54: 4-12.

Benton, S. L., and W. E. Cashin. 2012. Idea Paper\# 50 Student Ratings of Teaching: A Summary of Research and Literature. http://citeseerx.ist.psu.edu/viewdoc/summary?doi=10.1.1.388.8561.

Blair, E., and K. Valdez Noel. 2014. "Improving Higher Education Practice through Student Evaluation Systems." Assessment and Evaluation in Higher Education 39 (7): 879-894.

Blumberg, B., R. C. Cooper, and P. S. Schindler. 2011. Business Research Methods. 3rd ed. Maidenhead: McGraw-Hill.

Brandl, K., J. Mandel, and B. Winegarden. 2017. "Student Evaluation Team Focus Groups Increase Students'Satisfaction with the Overall Course Evaluation Process." Medical Education 51 (2): $215^{-227 .}$

Brockx, B., K. Van Roy, and D. Mortelmans. 2012."The Student as a Commentator: Students'Comments in Student Evaluations of Teaching." Procedia - Social and Behavioral Sciences 69: 1122-1133.

Cathcart, A., D. Greer, and L. Neale. 2014. "Learner Focused Evaluation Cycles: Facilitating Learning and Using Feedforward, Concurrent and Feedback Evaluation." Assessment and Evaluation in Higher Education 39 (7): 790-802.

Chad, P. 2012. "The Use of Team-Based Learning as an Approach to Increased Engagement and Learning for Marketing Students: A Case Study.” Journal of Marketing Education 34 (2): $128-139$.

Chambers, T. 2010."What I HearYou Saying is..: Analysis of Student Comments from the NSSE..." College Student Journal 44 (1): 3-24. Chapple, M., and R. Murphy. 1996. "The Nominal Group Technique: Extending the Evaluation of Student's Teaching and Learning." Assessment and Evaluation in Higher Education 21 (2): 147-160.

Chen, Y., and L. B. Hoshower. 2003. "Student Evaluation of Teaching Effectiveness: An Assessment of Student Perception and Motivation." Assessment and Evaluation in Higher Education 28 (1): $71-88$.

Chulkov, D. V., and J. van Alstine. 2012. "Challenges in Designing Student Teaching Evaluations in a Business Program.” International Journal of Educational Management 26 (2): 162-174.

Cook-Sather, A. 2006. "Sound, Presence, and Power:'Student Voice'in Educational Research and Reform."Curriculum Inquiry 36 (4): 359-390.

Crumbley, L., B. K. Henry, and S. H. Kratchman. 2001. "Students' Perceptions of the Evaluation of College Teaching." Quality Assurance in Education 9 (4): 197-207.

Darwin, S. 2017. "What Contemporary Work Are Student Ratings Actually Doing in Higher Education?"Studies in Educational Evaluation 54: 13-21. 
Davison, E., and J. Price. 2009. "How Do We Rate? An Evaluation of Online Student Evaluations." Assessment \& Evaluation in Higher Education 34 (1): $51-65$. doi:10.1080/02602930801895695.

Dobbie, A., M. Rhodes, J. W. Tysinger, and J. Freeman. 2004. "Using a Modified Nominal Group Technique as a Curriculum Evaluation Tool." Family Medicine-Kansas City 36: 402-406.

Dommeyer, C. J., P. Baum, K. Chapman, and R. Hanna. 2002. "Attitudes of Business Faculty towards Two Methods of Collecting Teaching Evaluations." Assessment and Evaluation in Higher Education 27 (5): 455-462.

Erikson, M., M. Erikson, and E. Punzi. 2016. "Student Response to a Reflective Course Evaluation." Reflective Practice 17 (6): 663-675.

Finelli, C. J., M. C. Wright, and T. Pinder-Grover. 2010. "Consulting the Delphi: A New Idea for Collecting Student Feedback through the Two Survey Method (TSM)." Journal of Faculty Development 24 (2): 25-33.

Freeman, R., and K. Dobbins. 2013. "Are We Serious about Enhancing Courses? Using the Principles of Assessment for Learning to Enhance Course Evaluation." Assessment \& Evaluation in Higher Education 38 (2): 142-151. doi:10.1080/02 602938.2011.611589.

Gaillard, F. D., S. P. Mitchell, and V. Kavota. 2011. "Students, Faculty, and Administrators' Perception of Students' Evaluations of Faculty in Higher Education Business Schools." Journal of College Teaching \& Learning 3 (8): 77-90.

Golding, C., and L. Adam. 2016. "Evaluate to Improve: Useful Approaches to Student Evaluation." Assessment \& Evaluation in Higher Education 41(1):1-14.

Grebennikov, L., and M. Shah. 2012. "Commencing Student Experience: New Insights and Implications for Action." European Journal of Higher Education 2 (2-3): 267-289.

Grebennikov, L., and M. Shah. 2013. "Student Voice: Using Qualitative Feedback from Students to Enhance Their University Experience." Teaching in Higher Education 18: 606-618.

Grebennikov, L., and M. Shah. 2017."Monitoring Trends in Research Student Experience."International Journal of Educational Management 31 (2): 118-130.

Guder, F., and M. Malliaris. 2013. "Online Course Evaluations Response Rates." American Journal of Business Education 6: 333-337.

Harper, S. R., and G. D. Khu. 2007. "Myths and Misconceptions about Using Qualitative Methods in Assessment." New Directions for Institutional Research 136: 5-14.

Hoon, A., E. Oliver, K. Szpakowska, and P. Newton. 2015. "Use of the 'Stop, Start, Continue' Method is Associated with the Production of Constructive Qualitative Feedback by Students in Higher Education." Assessment \& Evaluation in Higher Education 40 (5): 755-767. doi:10.1080/02602938.2014.956282.

Hsieh, H. F., and S. E. Shannon. 2005. "Three Approaches to Qualitative Content Analysis." Qualitative Health Research 15 (9): 1277-1288.

Huxham, M., P. Laybourn, S. Cairncross, M. Gray, N. Brown, J. Goldfinch, and S. Earl. 2008. "Collecting Student Feedback: A Comparison of Questionnaires and Other Methods." Assessment \& Evaluation in Higher Education 33 (6): 675-686. Kabanoff, B., A. Richardson, and S. Brown. 2003."Business Graduates'Perception of the Quality of Their Course: A View from TheirWorkplace." Journal of Institutional Research 12(2):1. 
Kember, D., D. Leung, and K. Kwan. 2002. "Does the Use of Student Feedback Questionnaires Improve the Overall Quality of Teaching and Learning?" Assessment and Evaluation in Higher Education 27 (5): 411-426.

Kindred, J., and S. N. Mohammed. 2005. "He Will Crush You Like an Academic Ninja!': Exploring Teacher Ratings on Ratemyprofessors.Com." Journal of Computer-Mediated Communication 10 (3).

Linse, A. R. 2017. "Interpreting and Using Student Ratings Data: Guidance for Faculty Serving as Administrators and on Evaluation Committees." Studies in Educational Evaluation 54: 94-106.

Mohammed, T. A., and S. M. Pandhiani. 2017. "Analysis of Factors Affecting Student Evaluation of Teaching Effectiveness in Saudi Higher Education: The Case of Jubail University College." AmericanJournal of Educational Research 5(5):464-475. doi:10.12691/education-5-5-2.

Nestel, D., A. Ivkovic, R. A. Hill, A. N. Warrens, P. A. Paraskevas, J. A. McDonnell, R. S. Mudarikwa, and C. Browne. 2012. "Benefits and Challenges of Focus Groups in the Evaluation of a New Graduate Entry Medical Programme.” Assessment \& Evaluation in Higher Education 37 (1): 117.

Newton, P. M., M. J. Wallace, and J. McKimm. 2012. "Improved Quality and Quantity of Written Feedback is Associated with a Structured Feedback Proforma." Journal of Educational Evaluation for Health Professions 9: 1-7. doi:10.3352/ jeehp.2012.9.10.

Penny, A. R. 2003. "Changing the Agenda for Research into Students' Views about University Teaching: Four Shortcomings of SRT Research." Teaching in Higher Education 8 (3): 399-411.

Richardson, J. 2005. "Instruments for Obtaining Student Feedback: A Review of the Literature." Assessment and Evaluation in Higher Education 30 (4): 387-415.

Scott, G., L. Grebennikov, and M. Shah. 2008. Using Qualitative Data to Prove and Improve Quality in Australian Higher Education. Melbourne: In Australasian Higher Education Evaluation Forum.

Shah, M., and C. S. Nair. 2009. "Using Student Voice to Improve Student Satisfaction: Two Australian Universities the Same Agenda." Journal of Institutional Research 7 (2): 43-55.

Smith, C. 2008. "Building Effectiveness in Teaching through Targeted Evaluation and Response: Connecting Evaluation to Teaching Improvement in Higher Education." Assessment \& Evaluation in Higher Education 33 (5): 517-533.

Smithson, J., M. Birks, G. Harrison, C. S. Nair, and M. Hitchins. 2015. "Benchmarking for the Effective Use of Student Evaluation Data." Quality Assurance in Education 23 (1): 20-29.

Spencer, K. J., and L. P. Schmelkin. 2002. "Student Perspectives on Teaching and Its Evaluation." Assessment and Evaluation in Higher Education 27 (5): 397-410.

Spooren, P., B. Brockx, and D. Mortelmans. 2013."On the Validity of Student Evaluation of Teaching: State of the Art." Review of Educational Research 83 (4): 598-642.

Stein, S. J., D. Spiller, S. Terry, T. Harris, L. Deaker, and J. Kennedy. 2013. "Tertiary Teachers and Student Evaluations: Never the Twain Shall Meet?"Assessment \& Evaluation in Higher Education 38 (7): 892-904. doi:10.1080/02602938.2013.767876.

Stupans, I., T. McGuren, and A. M. Babey. 2016."Student Evaluation of Teaching: A Study Exploring Student Rating Instrument Free-Form Text Comments." Innovative Higher Education 41 (1): 33-42.

Trigwell, K., K. Caballero Rodriguez, and F. Han. 2012."Assessing the Impact of a University Teaching Development Program." Assessment \& Evaluation in Higher Education 37 (4): 499-511. 
Varga-Atkins, T., J. McIsaac, and I. Willis. 2017. "Focus Group Meets Nominal Group Technique: An Effective Combination for Student Evaluation?” Innovations in Education and Teaching International 54 (4): 289-300.

Veeck, A., K. O'Reilly, A. MacMillan, and H. Yu. 2016. “The Use of Collaborative Midterm Student Evaluation to Provide Actionable Results." Journal of Marketing Education 38 (3):157-169.

Wickramasinghe, S. R., and W. M. Timpson. 2006. "Mid-semester Student Feedback Enhances Student Learning." Education for Chemical Engineers 1(1): 126-133.

Wolbring, T., and E. Treischl. 2016. "Selection Bias in Students' Evaluation of Teaching." Research in Higher Education 57 (1): 51-71.

Wongsurawat, W. 2011. "What's a Comment worth? How to Better Understand Student Evaluations of Teaching." Quality Assurance in Education 19 (1): 67-83.

Zhao, J., and D. J. Gallant. 2012. "Student Evaluation of Instruction in Higher Education: Exploring Issues of Validity and Reliability." Assessment \& Evaluation in Higher Education 37 (2): 227-235. 